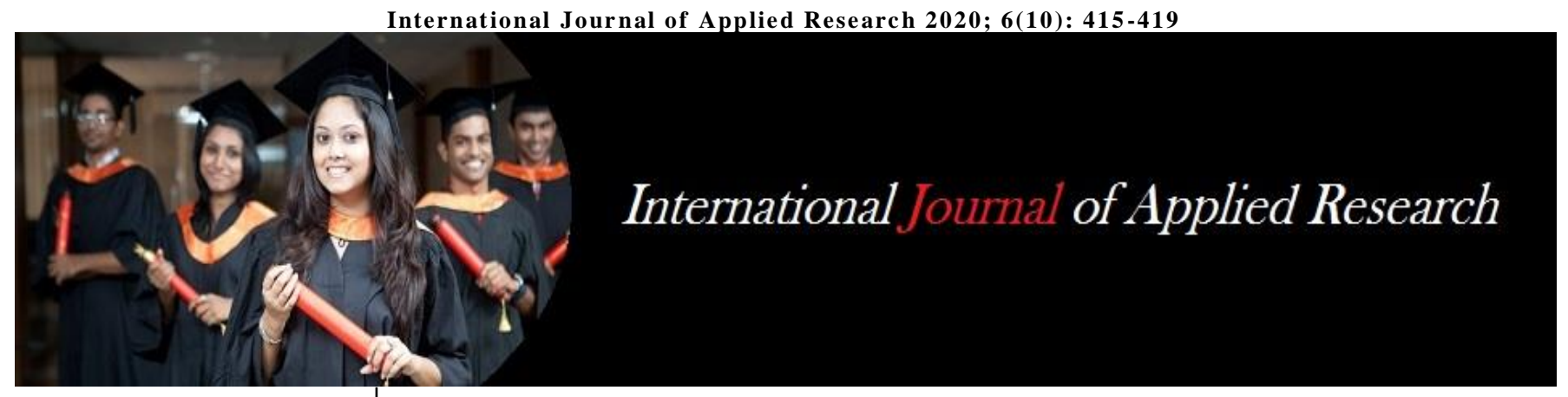

ISSN Print: $2394-7500$ ISSN Online: 2394-5869 Impact Factor: 5.2

IJAR 2020; 6(10): 415-419 www.allresearchjournal.com

Received: 16-08-2020 Accepted: 19-09-2020

Dr. Rita Kumari

Deptt. Of Psychology L.N.M.U., Darbhanga Bajitpur, Pidhauli, Teghra, Begusarai, Bihar, India
Corresponding Author: Dr. Rita Kumari Deptt. Of Psychology L.N.M.U., Darbhanga Bajitpur, Pidhauli, Teghra, Begusarai, Bihar, India

\section{The psychological effects of covid-19 pandemic on society}

\section{Dr. Rita Kumari}

DOI: https://doi.org/10.22271/allresearch.2020.v6.i10g.7338

\begin{abstract}
Going by the current physical reach of the Covid-19 pandemic in the population there are bound to be long-term implications in terms of socio-economic and psychological impact, the swift rise of fear and anxiety among people due to uncertainty of the disease are coupled with essential yet socially disruptive measures like lockdowns and quarantines. These can lead to significant psychological and psychiatric disturbances such as post-traumatic stress disorder, depression, anxiety, panic disorders, and behavioural disorders. Predisposing factors include staying away from family, loneliness, misinformation on social media, financial insecurity and stigmatization. Healthcare workers have a high risk of developing post traumatic stress disorder and burnout; therefore, it is paramount to understand and research the psychological impact and key determinants to prevent, identify, and manage such problems. Suggested actions include support lines for anxious people, tele-counselling, virtual connecting \& help groups, encouraging meditation, conduction research on psychological consequences, and developing and utilising suitable interventions.
\end{abstract}

Keywords: Coronavirus; covid-19; mental health; pandemic; psychology; PTSD; self-isolation; social distancing; quarantine

\section{Introduction}

Pandemics are diseases that occur from time to time throughout human history, causing millions of people to die and negatively affecting public mental health. According to the World Health Organization, (2020) pandemic is the spread of a new disease worldwide, which has caused many people to be harmed and also killed many people. Pandemics have been seen in many periouds throughout history. Each pandemic negatively affected humanity sociologically, economically and psychologically. For example, pandemics such as influenza, Severe Acute Respiratory Syndrome (SARS), Middle East Respiratory Syndrome (MERS) are among the pandemics that have negatively affected millions of people. Today, people are still struggling with a pandemic. Covid-19, which was first seen in Wuhan, China and then spread rapidly all over the world, affects the whole world deeply. Covid-19 also affected many people and caused many people to lose their lives shortly after emerging like other pandemics (World Health Organization, 2020).

Currently, humanity is in the middle of a process that must be rigorously managed to this context, it is necessary to reveal scientific researches about COVID-19 and to discuss the short and long term effects of it on people. Scientific research on COVID-19 is of great importance in order to prevent the destructiveness of it in social, political, psychological and economic dimensions. In this study, it was aimed to keep a projection on how COVID-19 could affect people psychologically by starting from the psychological negative effects of epidemics and natural disasters that have affected humanity in the past. In this context, recommendations were made regarding the measures to eliminate the negativities in the short and long term.

The sudden outbreak of a serious respiratory illness in China followed by rapid spread to other parts of the world promoted researchers to study the disease and to isolate the virus without much delay, We now know that the disease is caused by a previously unknown virus: 2019-nCoV or SARS-CoV2. The uncertainty of the disease is a major reason for psychological stress among people. With the WHO declaring it a pandemic on $11^{\text {th }}$ March 2020 , there was a swift rise of fear and anxiety among the general population. 
Previous data on mass occurrences, like natural disasters, shows that large scale disruptive events are strongly associated with ill-effects on mental health - post traumatic stress disorder (PTSD) being the most frequently encountered followed by depression, anxiety, and other behavioral \& psychological disorders. Therefore, the current pandemic poses a great risk for psychological and psychiatric morbidity. The disease caused by a hitherto unrecognized infection with no vaccines or approved drug regimens in place further adds to the distress.

While researchers toiled to develop vaccines and drugs, the most successful intervention to slow the spread of disease was found to by quarantining people in their homes. Reducing physical interaction, popularly known as 'social distancing', has been advertised by many countries. However, after people failed to practice adequate social distancing during initial stages, severely affected countries like China and Italy had to switch to strict lockdown and quarantine of the citizens. As more countries opt. for lockdown, the long-term psychological impact of the circumstances remains debatable. There is very limited data available on the mental health aspect of previous medical outbreaks. Some literature shows that life threatening medical illnesses can lead to symptoms associated with PTSD following recovery. The question thus arises: are we healing towards a mental health catastrophe ?

\section{The Vulnerable}

WHO recently changed the term 'social distancing' to 'physical distancing' to make people feel less lonely and isolated. An earlier meta-analysis had concluded that loneliness is a risk factor for all-cause mortality. People living away from their families for education or work, or otherwise separated from their loved ones are at a higher risk for developing mental health problems such as depression, anxiety, etc. Elderly people living alone are also greatly predisposed.

While social media is aiding people in being more connected in times of physical isolation. It is also a major source of rumors and false information adding to the stress. The hourly updates on death tolls and rising case numbers can be consuming, especially for people predisposed to medical health issues or already on medications for psychiatric disorders. Furthermore, lockdown has already caused many manufacturing industries to shut down and businesses to incur severe losses. The enormous hit on the economy has caused financial insecurity and stress in the population which will indirectly have consequences on health. Most shaken up are the daily wage workers who do not have access to their sustenance income.

Suspected cases and confirmed patients perhaps suffer the most in feeling stigmatized by the community for carrying an infection that may inadvertently affect other people. Being unable to meet their close ones in isolation can add to their suffering. The uncertainty about the severity of infection and unsureness of the treatment effectiveness may be the determinants of utmost importance.

\section{Expected Consequences}

The sudden panic created recently with people hoarding supplies is an indication to perhaps expect a rise in cases of panic disorders. With more people staying indoors, there is a likelihood for the development of anxiety related to claustrophobia. Inaccessibility to drugs will escalate withdrawal syndromes in addicts and people who regularly abuse substances.

In addition, there may also be a step rise of somatoform disorders as the outbreak peaks and then settles down. Therefore, mental health crisis is inevitable during and after the pandemic. The mental health effects of COVID-19 will further affect physical health after the outbreak. Therefore, it is important to understand and research the psychological impact of the pandemic to better prepare physicians, irrespective of their field of specialization. To actively look for such signs in their patients. This will aid in early identification and management of a large-scale influx of patients with behavioral and psychological problems.

A stumbling block in providing healthcare to a vast magnitude of population is the underequipped and moderately provisioned healthcare set up along with limited number of psychiatric and psychological health providers in the country. Hence, the pandemic should serve as a wakeup call to invest adequately and strengthen our healthcare system so that the country is better equipped to fight all medical battles.

\section{COVID-19 Pandemic Psychology}

Pandemics have devastating effects on not only the psychology of people experiencing the pandemic during the process, but even the psychology of future people. Pandemics such as HIV/ AIDS, influenza, SARS, MERS, which have appeared in the past and threatened the health of people, have also led to negative consequences in people's psychology. Considering the effects of pandemics on the groups of people living in the community, it can be seen that it affects directly patients, and their relatives, healthcare staff, and all other people who are at risk of disease (Morganstein et al. 2017). The psychological reaction of each person in the face of intense stress and fear caused by pandemics can be different. It has been observed that pandemics cause psychological effects such as depression, anxiety, fear of death, losing loved ones, posttraumatic stress disorder, psychotic symptoms and mourning in general (Taylor 2019). However, some people can control the negative emotions of pandemics and continue their lives normally. But some people cannot cope with these feelings and need professional support. In this regard, the negative consequences for individuals and the society from the beginning of its spread to its control are regarded as unpredictable disaster.

Physiologically and psychologically the most affected people by the COVID-19 pandemic are those who suffer from the pandemic. In the studies examining the psychological effects of COVID-19 on patients, as seen in other epidemics that most patients face negative psychological conditions such as posttraumatic stress disorder, anxiety, depression, loneliness, distress, fear, anger and fear of being tagged (Bo et al. 2020; Wu, Chan and Ma 2005; Cheng et al. 2004) [11, 17]. Indeed, large-scale destructive events such as natural disasters and wars in the past have been known to affect people's psychological health negatively. In such cases, the most common behavioral and psychological disorders are reported to be depression, anger, anxiety, low self-esteem and posttraumatic stress disorder (PTSD) (Arpaci et al., 2020b; Nigam and Kumar $2020^{[3]}$; Steinberg and Daniel 2020; Sood 2020). For example, Van Bortel et al. (2015) examined the psychosocial effects caused by the ebola 
pandemic. In their study, they started that ebola has personal, social and global effects. These effects are generally expressed as fear and anxiety, shame, mourning, loss of confidence, trauma, discrimination and psychological disorders. In different studies, it has been reported that COVID-19 epidemic has many mental problems including anxiety, depression and stress; as well as psychological problems including PTSD, sleep disorders and etc. in both the healthcare staff and the public (Hu et al. 2020; Liu et al. 2020; Kang et al. 2020; Sun et al. 2020; Xiang et al., 2020) ${ }^{[20,16]}$. At the same time, researchers predict that COVID-19 epidemic will cause problems such as extreme fear of disease, anger, increased alcohol and tobacco use, acute stress disorder, schizophrenia and suicidal tendencies ( $\mathrm{Hu}$ et al. 2020; Huang and Liu 2020; Li et al. 2020; Dai et al. 2020) ${ }^{[20,14,16]}$. On the other hand, hypochondriasis can be seen in people who have been exposed to the disease and recovered or who have never been infected. The continuous exposure of people to information, news and videos about a disease, as in COVID-19, cause hypochondriasis (Marcus et al. 2007). COVID-19 is the most mentioned topic in almost every mass media for the last 6 months. In this context, intense exposure to COVID-19 is predicted to increase the likelihood of hypochondriasis in today's people.

\section{Psychological Effect of COVID-19}

Like the traumatic experiences that have caused many psychological problem on humans throughout history, COVID-19 will have a negative psychological effect on every person. In this context, children are one of the groups most affected by destructive events such as pandemic, war, forced migration, and natural disaster. It is thought that compared to other age groups, children will be more negatively affected psychologically because of the difficulty of making sense of all these COVID-19 experiences and lack of self-expression skills. In their study on the SARS pandemic's psychological effect on children, Tsand, Scudds and Chan (2004) ${ }^{[11]}$ stated that the children in families who have a pandemic in their family members show excessive crying behavior, have difficulty in sleeping and fell embarrassed. Wang, Zhang, Zhao, Zhang, and Jiang (2020) stated that children may face many psychological problems such as the fear of getting infected with the COVID-19 epidemic, anxiety and frustration, and troubles because of the shortage of social interaction. In this sense, it can be claimed that children who are adults of the future are at a great psychological risk.

Another group negatively affected by the pandemic of COVID-19 is young people. It may be brought that young people will be less psychologically affected by COVID-19 due to the low death rate because of COVID-19 and the ability to easily overcome the physiological symptoms caused by the virus. However, it is predicted that young people will be negatively affected by this pandemic process and will experience psychological problems. As a matter of fact, Sim et. at. (2010), concluded that psychological problem was associated with being in their study examining the psychological effects of epidemics. Al-Rabiaah et al. (2020) in their study on the relationship between MERS pandemics and stress in university students concluded that $77 \%$ of the students has low, $18.4 \%$ has medium level of anxiety. Likewise, Wang and others (2020) found that young people are more affected by the epidemic psychologically and feel more stressed, anxious, intolerant, and depressed in their study in which they investigated the psychological effects of the COVID-19 epidemic in China (Wang et al. 2020) ${ }^{[10]}$. It is also stated that just as seen in other pandemics, intolerance to uncertainty can be observed in COVID-19. It is stated that intolerance of uncertainty is associated with psychological disorders such as depression and anxiety (Shapiro, Gros and MeCabe 2020; Wheaton and Ward 2020). In addition, studies conducted on the psychological effects of COVID-19 in youth have shown that psychological problems such as depression, distress, anxiety, irritability, sadness, and fear are observed (Arpaci et al., 2020a; Huang and Zhao 2020; PEW 2020; Cao et al. 2020; Huang, Xu and Liu 2020) ${ }^{[9,15,6,14]}$. In addition, it is reported that Chinese international university students may be negatively affected psychologically because of racism and alienation that may cause psychological disorders (Zhai and Du 2020). Quarantine and home isolation are one of the most important issues in the investigation of the psychological impact of the COVIC-19 epidemic. During the period when COVID-19 began to emerge and spread, the education process of the youth continued. Because of the rapid spread of the epidemic and the increase of deaths in many countries young people have stopped their education and stayed in their homes. Therefore, the likelihood of loneliness and depression increase in young people whose education process is negatively affected and their social relations are disrupted. Although they can continue their social relations through internet and social media applications, it is obvious that they will not be as healthy and high quality as social relations established face to face. This situation can be claimed to decrease the relationships and life satisfaction. At the same time, due to the development of technology, compared to other age groups young people can be exposed to negative flows caused by the COVID-19 epidemic around the world through internet and social media. This situation can be claimed to make young people psychologically more risky than other age groups. In other words, although variables such as life styles, physical strength, developmental characteristics and less possibility of being affected by the virus that caused the epidemic may provide them a protective role against the COVID-19 epidemic, just the opposite they may also become risk factors. In general, although virus-related deaths ae not common among young people (Worldometers 2020), there is a great deal of restriction in their social life and uncertainty about when this isolation process will end. Therefore young people are thought to have psychological consequences such as loneliness, depression, anger, pessimism, and hopelessness.

Another group affected by COVID-19 is middle-aged and elderly people. When we look at the COVID-19 Fatality Rate by AGE, age level of people who died because of COVID-19 is seen as "80+ years old $21-9 \%$, 70-79 years old 8.0\%, 60-69 years old 3.6" (World ometers 2020). It is anticipated that the elderly people, who are the most probable group with COVID-19 deaths, will experience high levels of stress and fear against the virus. As a matter of fact, it was determined that psychological problems such as depression, anxiety, and psychological distress were observed in the elderly people in studies on the psychological effect of COVID-19 (Kong et al. 2020; Wang et al. 2020) ${ }^{[10]}$. In this regard, it is claimed that the cognitive and emotional disorders of elderly people may increase because of COVID-19 and existing psychological disorders 
can be triggered (Yang et al. 2020). In this regard, the high risk of death of the elderly people because of COVID-19 makes them psychologically more vulnerable.

\section{COVID-19 on Education Reflections}

COVID-19 pandemic disrupted the students 'educational process. Billions of students and millions of education are affected by school closures and other restrictions. Social distancing and other limitations due to COVID-19 may cause negative psychological conditions such as anxiety and fear, and these may affect the well-being of students and parent (Ozer, 2020). Most governments around the world have temporarily closed educational institutions in an attempt to contain the spread of the COVID-19 pandemic. These nationwide closures are impacting over $60 \%$ of the world's student population. Several other countries have implemented localized closures impacting millions of additional learners (UNESCO, 2020). Millions of students have not been able to continue learning in schools, universities, vocational training institutions and audit learning programmes. Many governments responded to the pressing need to provide school children with learning possibilities via online and distance learning (Romer, 2020). Although precautions were taken, the students' learning process was negatively affected. Students who have been stripped of their freedom due to COVID-19 are deeply concerned about when face to face education will happen.

Education has been hit particularly hard by the COVID-19 pandemic with 1.53 billion learners out of school and 184 country-wide school closures, impacting $87.6 \%$ of the world's total enrolled learners (Education Cannot Wait (ECW), 2020). School closures could prevent the rapid spread of the epidemic. Its seem to be the optimal solution in the short term. School closures can affect deaths during an outbreak either positively, through reducing transmission and the number of cases, or negatively, through reductions in the health-care workforce available to care for those who are sick (Viner et al. 2020). However, when school closures take longer, students 'learning and social relationships are negatively affected. Schools provide face-to-face education. But because face-to-face education cannot take place because of the epidemic, the country's education administrators want students to be accessible through distance or online education (Reimers \& Schleicher, 2020). This in itself harbors a problem. Because online education requires an excellent infrastructure. Every student needs to be accessible to online or distance education. But unfortunately access to the internet is not the same everywhere. Likewise, not every student has their own PC. Moreover, some regions of the world do not even have electricity. Even if the infrastructure problems are resolved in some way, the constant exposure of students to distance or online education is tedious to them. For this reason, the motivation of the students for learning decreases and the learning goals are not achieved. Not only students but also teachers and families are affected by the negative effects of the COVID-19 pandemic on education. Families may not have enough support for their children to learn at home. This may be due to low socio-economic level of families, as well as low educational level of family members. Likewise, teachers have an important role in the success of the educational process. But most teachers lacked pedagogical competence about how to manage the teacher distance or online education process. They didn't know how to develop distance or online educational tools (Rapanta et al., 2020). Therefore, the negative effects of the outbreak seem to be more difficult to compensate for for the students.

Going to school is the best public policy tool available to raise skills. While school time can be fun and can raise social skills and social awareness, from an economic point of view the primary point of being in school is that it increases a child's ability (Burgess \& Sievertsen, 2020). According to Reimers (2020) for the vast majority of children who loose opportunities to learn because of the pandemic, it will be hard to recover from those losses, the harder the longer the period of physical isolation from other students and teachers. The educational disadvantages such losses generate will beget more educational, and eventually economic and social disadvantage. Because these losses will be experienced by large segments of the population, societies will suffer as their productivity is diminished.

The fight against the COVID-19 pandemic is global as well as on a national basis. Therefore, not only healthcare staff, every person should support each other in this process and healthcare staff should know that they are not alone. Therefore, it may be suggested to carry out activities that will increase the morale and motivation of healthcare staff at national and global level.

\section{References}

1. World Health Organization: Data on SARS, Geneva: WHO; 2003 [cited 2020 Mar 31]. Available from 2003. http://www.who.int/cst/sars/country/en/country2003_08 -15.pdf

2. World Health Organization: Coronavirus disease (COVID-19) Pandemic, Geneva: WHO; [cited 2020 Mar 31]. Available from 2020.

https://www.who.int/emergenceies/diseases/novelcoronavirus, 2019

3. Nigam C, Kumar A. Covid-19 pandemic: Depression, anxiety go viral as nation observes lockdown. India today [Internet]. [cited 2020 Mar 31]. Available from 2020.

https://www.indiatoday.in/mail/today/story/covid-19 pandemic-depression-anxiety-viral-nations-observeslockdown-1659774-2020-03-26

4. Wu KK, Chan SK, Ma TM. Posttraumatic stress after SARS. Emerge Infect Dis 2005;11(8):1297-300. doi:10.3201/eid1108.041083.

5. Sim K, Chau HC. The psychological impact of SARS: a matter of heart and mind. CMAJ 2004;170(5):811-2. doi: 10.1503/cmaj.1032003.

6. Lai J, Ma S, Wang Y, Cao Z, Hu J, Wei N et al. Factors associated with mental health. Outcomes among health care workers exposed to Coronavirus disease 2019. JAMA Netw. Open 2020;3(3):c203976.

doi:10.1001/jamanetworkopen. 2020.3976

7. Garg K, Kumar CN, Chandra PS. Number of psychiatrists in India: Baby steps forwad, but a long way to go. Indian J Psychiatry 2019;61:104-5.

8. Alsubaie S, Hani Temsah M, Al-Eyadhy AA, Gossady I, Hasan GM, Al-Rabiaah A et al. The Journal of Infection in Developing Countries 2019;13(10):920926. http://dx.doi.org/10.3855/jide. 11753

9. Arpati I, Alshehabi S, Al-Emran M, Khasawneh M, Mahariq I, Abdelijawad T et al. Analysis of Twitter data using evolutionary clustering during the COVID- 
19 Pandemic, CMC-Computers, Materials \& Continua 2020a;65(1):193-204. https://doi.org/10.32604/cmc.2020.011489

10. Bo H, Li W, Yang Y, Wang Y, Zhang Q, Cheung T et al. Posttraumatic stress symptoms and attitude toward crisis mental health services among clinically stable patient with COVID-19 in China. Psychological Medicine 2020, 1-7. http://dx.doi.org/10.1017/S0033291720000999

11. Chan AO, Huak CY. Psychological impact of the 2003 severe actual respiratory syndrome outbreak on health care workers in a medium size regional general hospital in Singapore. Occupational Medicine 2004;54(3):190196. http://dx.doi.org/10.1093/occmed/kqh027

12. Chong MY, Wang WC, Hsieh WC, Lee CY, Chiu NM, Yeh WC et al, Psychological impact of severe acute respiratory syndrome on health workers in a tertiary hospital. British Journal of Psychiatry 2004;185:127133. http://dx.doi.org/10.1192/bjp.185.2.127

13. Education Cannot Wait (ECW) Covid-19 and education in emergencies. https://www.educationcannotwait.org/covid-19, 2020).

14. Huang I, Xu F, Liu H. Emotional responses and coping strategies of nurses and nursing college students during COVID-19 outbreak. Medrxiv 2020. http://dx.doi.org/10.1101/2020.03.05.20031898

15. Huang Y, Zhao N. Generalized anxiety disorder, depressive symptoms and sleep quality during. Medrxiv 2020. http://dx.doi.org/10.1101/2020.02.19.20025395

16. Kang L, Li Y, Hu S, Chen M, Yang C, Yang BX, et al. The mental health of medical workers in Wuhan, China dealing with the 2019 novel coronavirus. Correspondence 2020;7(3):14. http://dx.doi.org/10.1016/S2215-0366(20)30047-X

17. Kong X, Zheng K, Tang M, Kong F, Zhou J, Diao L et al. Prevalence and factors associated with depression and anxiety of hospitalized patients with COVID-19, MedRxiv 2020. http://dx.doi.org/10.1101/2020.03.24.20043075

18. Lai J, Ma S, Wang Y, Cai Z, Hu J, Wei N et al. Factors Associated With Mental Health Outcomes Among Health Care Workers Exposed to Coronavirus Disease 2019. JAMA Network Open 2020;3(3):1-12. http://dx.doi.org/10.1001/jamanetworkopen.2020.3976

19. Lee SM, Kang WS, Cho AR, Kim T, Park JK. Psychological impact of the 2015 MERS outbreak on hospital workers and quarantined hemodialysis patients. Comprehensive Psychiatry 2018;87:123-127. http://dx.doi.org/10.1016/j.comppsych.2018.10.003

20. Liu JJ, Bao Y, Huang X, Shi J, Lu L. Mental health considerations for children quarantined because of COVID-19. The Lancet Child \& Adolescent Health 2020, 1-2.00 